\title{
Characterization and Mineralization of Strontium Doped Nano Hydroxyapatite Coating on Titanium Rods
}

\author{
Chuang WANG ${ }^{1}$, Qian LI ${ }^{1,2}$, Jianhai YANG $^{3}$, Tao FU $^{4}$, Yougui JIANG ${ }^{5}$, Meng FENG ${ }^{1}$, \\ Yusheng QIU ${ }^{1}$, Xing MA ${ }^{1 *}$
}

${ }^{1}$ Department of Orthopaedics, The First Affiliated Hospital, Xi'an Jiaotong University, No.277, Yanta West Road, Xi'an,
Shaanxi, 710061, P.R. China
${ }^{2}$ Department of Orthopaedics, The NO.1 Hospital of Shijiazhuang, No. 36, Fan Xi Road, Shijiazhuang, Hebei, 050011,
P.R. China
${ }^{3}$ School of Aerospace, Xi'an Jiaotong University, No.28, Xianning West Road, Xi'an, Shaanxi, 710049, P.R. China
${ }^{4}$ Key Laboratory of Biomedical Information Engineering of Ministry of Education, School of Life Science and Technology,
Xi'an Jiaotong University, No.28, Xianning West Road, Xi'an, Shaanxi, 710049, P.R. China
${ }^{5}$ Department of Dermatology, The Second Affiliated Hospital, Xi'an Jiaotong University, No.157, West Five Road, Xi'an,
Shaanxi, 710004, P.R. China

crossref http://dx.doi.org/10.5755/j01.ms.23.3.17254

Received 13 December 2016; accepted 26 January 2017

\begin{abstract}
Pure nano hydroxyapatite (nHA) and strontium doped nano hydroxyapatite ( $\mathrm{Sr}-\mathrm{nHA}, \mathrm{Sr} /(\mathrm{Ca}+\mathrm{Sr})=10 \%$, atomic ratio) were prepared by a one-step method involving homogeneous phase co-precipitation. Fourier transform infrared spectroscopy (FT-IR) revealed $\mathrm{OH}^{-}, \mathrm{PO}_{4}{ }^{3-}$ and $\mathrm{CO}_{3}{ }^{2-}$ groups in both powders. X-ray diffraction (XRD) showed that the peaks of Sr-nHA shifted to lower $2 \theta$ values compared with those of pure nHA. Both the pure nHA $(39.5 \pm 11.2 \mathrm{~nm}$ in length and $15.9 \pm 3.7 \mathrm{~nm}$ in width) and Sr-nHA $(33.0 \pm 10.2 \mathrm{~nm}$ in length and $13.2 \pm 3.2 \mathrm{~nm}$ in width) powders showed tiny nano-rod feature. Moreover, TC4 (Ti-6Al-4V) rods ( $1 \mathrm{~mm}$ in diameter and $20 \mathrm{~mm}$ in length) coated with pure nHA or Sr-nHA were prepared by high-energy plasma spraying. Elements of $\mathrm{Ca}, \mathrm{P}, \mathrm{O}$ and $\mathrm{Sr}$ were detected on the $\mathrm{Sr}-\mathrm{nHA}$ coating surface by energy dispersive spectrometry (EDS). XRD result also indicated the nearly unchanged phase composition after spraying. By immersion in the simulated body fluid (SBF), in vitro mineralization ability was estimated and the surface layers were evaluated by scanning electron microscopy (SEM) and XRD. The results showed that Sr-nHA coating had better mineralization ability than the pure nHA coating. Therefore, the synthesized Sr-nHA and its sprayed coatings would have potential application for surface modification of biological prostheses and other implantable materials.

Keywords: hydroxyapatite (HA), strontium (Sr), plasma spraying, nanomaterial.
\end{abstract}

\section{INTRODUCTION}

With the gradual aging of population, more and more people will face the senile disease. It is known that, osteoporosis (OP), one of the most common senile diseases, is an increasingly serious problem in the aging population and causes serious social medical-economic burdens and a series of physiological and psychological problems [1-4]. Because of the tough challenges caused by OP or osteoporotic fractures, the past few decades have been an important time for the development of new biomaterials [5, 6]. Lots of biocompatible and bioactive materials therefore have been well designed and studied [7-10].

Hydroxyapatite (HA) has become one of the most popular materials, which has been widely used in bone implants including the coating of prosthesis due to its satisfactory biocompatibility and osteo-conductivity [11-14]. However, for patients with osteoporosis, pure HA has little effects on promoting bone formation or suppressing bone resorption. Thus the loose rate of pure HA coated implants is high. It is of significance to achieve

\footnotetext{
* Corresponding author. Tel.: +86-29-85322935; fax: +86-29-85322938.

E-mail address: maxing2826@mail.xjtu.edu.cn (X. MA)
}

more stable binding between implants and human bone tissues and reduce incidence of loosening and failure after internal fixation or arthroplasty for patients with osteoporosis.

In order to improve the functions of HA, various ionsubstituted HA have been prepared, such as strontium $(\mathrm{Sr})$, silicon $(\mathrm{Si})$, magnesium $(\mathrm{Mg})$, zinc $(\mathrm{Zn})$, europium $(\mathrm{Eu})$, cobalt (Co) [15-18]. Among these ions, Sr has been a research focus because it could simultaneously promote bone formation and inhibit bone deterioration [11-13, $19-21]$. Over the years, many efforts were made for novel Sr-substituted HA biomaterials through a variety of methods (such as electrochemical deposition, sol-gel, ion beam sputter deposition, coating sintering, bionic solution growing and so on). On the other hand, it is evident that $\mathrm{Sr}$ doped HA with appropriate atomic ratio of $\mathrm{Sr} /(\mathrm{Ca}+\mathrm{Sr})$, for example $10 \%$, is promising [22-26].

However, the above-mentioned methods are just for scientific research. Plasma spraying, a mainstream process for manufacturing clinical application materials, has not drawn enough attention in this field. In this study, we firstly synthesized pure nano hydroxyapatite (nHA) and $\mathrm{Sr}$ doped nano hydroxyapatite $(\mathrm{Sr}-\mathrm{nHA}, \mathrm{Sr} /(\mathrm{Ca}+\mathrm{Sr})=10 \%)$. Then the two kinds of nanomaterials were used for coating 
on TC4 (Ti-6Al-4V) rods by using a high-energy plasma spraying technique. Finally, the microstructure, phase composition and in vitro mineralization ability of the products were investigated. It is expected that this work could make a good foundation for our following cytological studies.

\section{EXPERIMENTAL DETAILS}

The pure nHA and Sr-nHA powders were prepared by our one-step method involving homogeneous phase coprecipitation, based on the following reaction:

$(10-\mathrm{x}) \mathrm{CaCl}_{2}+\mathrm{x} \mathrm{SrCl}_{2}+6 \mathrm{Na}_{3} \mathrm{PO}_{4}+2 \mathrm{NaOH}=\left(\mathrm{Ca}_{10-}\right.$ $\left.{ }_{x} \mathrm{Sr}_{\mathrm{x}}\right)\left(\mathrm{PO}_{4}\right)_{6}(\mathrm{OH})_{2}+20 \mathrm{NaCl}$

$10 \%$ Sr-nHA was designed and prepared by doping $\mathrm{Sr}$ ions into nHA with an atomic ratio of $\mathrm{Sr} /(\mathrm{Ca}+\mathrm{Sr})=\mathrm{x} /[(10-\mathrm{x})+\mathrm{x}]=1 /[(10-1)+1]=1 / 10(10 \%)$.

$\mathrm{CaCl}_{2}$ was purchased from Tianjin SHENTAI Chemical Industry CO., Ltd. $\mathrm{SrCl}_{2}$ was purchased from Tianjin TIANLI Chemical Reagents Ltd. $\mathrm{Na}_{3} \mathrm{PO}_{4}$ was purchased from Tianjin SHENGAO Chemical Reagents Ltd. $\mathrm{NaOH}$ was purchased from Tianjin YONGSHENG Fine Chemical Co. Ltd. All the reagents used were analytical grade chemicals. First, the solution of $\mathrm{CaCl}_{2}$ $(0.36 \mathrm{~mol} / \mathrm{l})$ and $\mathrm{SrCl}_{2}(0.04 \mathrm{~mol} / \mathrm{l})$ and the solution of $\mathrm{Na}_{3} \mathrm{PO}_{4}(0.24 \mathrm{~mol} / \mathrm{l})$ were well prepared with ultrapure water. The atomic ratio of $\mathrm{Sr} /(\mathrm{Ca}+\mathrm{Sr})$ was set as $10 \%$. Second, the two solutions were mixed under stirring at $37{ }^{\circ} \mathrm{C}$, and the $\mathrm{pH}$ was adjusted to 10 by drop-wise adding $1 \mathrm{~mol} / \mathrm{l} \mathrm{NaOH}$ solution [15]. The reaction continued under stirring at $37^{\circ} \mathrm{C}$ for $2 \mathrm{~h}$, and the white precipitate was obtained and thoroughly washed with ultrapure water by centrifugation at least 5 times. Third, the slurry was dried in an oven at $120^{\circ} \mathrm{C}$ for 3 days, and ground to fine powder. Pure nHA powder was also prepared as the control.

Before plasma spraying, TC4 rods (1 $\mathrm{mm}$ in diameter and $20 \mathrm{~mm}$ in length) was used as the substrates through deoil and gritblasted by machine. $10 \%$ Sr-nHA powder was evenly sprayed on the substrates by a high-energy plasma spray equipment (Sulzer Metco, METCO-9M, Switzerland), using the parameters shown in Table 1. The coating thickness, measured with vernier caliper, was $120-140 \mu \mathrm{m}$. As a control, pure nHA coating underwent the same working procedure.

Table 1. Plasma spraying parameters

\begin{tabular}{|c|c|}
\hline Argon plasma gas flow rate, $\mathrm{cfpm}^{\mathrm{a}}$ & $80-90$ \\
\hline Hydrogen plasma gas flow rate, $\mathrm{cfpm}^{\mathrm{a}}$ & $17.5-20$ \\
\hline Spray distance, $\mathrm{mm}$ & $90-100$ \\
\hline Current, $\mathrm{A}$ & 480 \\
\hline Voltage, $\mathrm{V}$ & 70 \\
\hline Powder feed rate, $\mathrm{g} / \mathrm{min}$ & 50 \\
\hline Maximum power, $\mathrm{KW}$ & 80 \\
\hline a cubic feet per minute & \\
\hline
\end{tabular}

Phase analyses of the nHA and Sr-nHA powders were characterized by using Fourier transform infrared spectroscopy (FT-IR, Thermo, Nicolet Avatar 330, USA) and X-Ray diffraction (XRD, Shimadzu, XRD-7000, Japan). The morphology of nHA and Sr-nHA powders were observed by transmission electron microscopy (TEM, Hitachi, H-7650, Japan).

Besides, scanning electron microscopy (SEM, Hitachi, TM-1000, Japan), XRD (PANalytical, Empyrean, Netherlands) and energy dispersive spectrometery (EDS, Oxford AE350, UK) were used for surface microstructural observation, phase and element analyses of nHA or $10 \%$ Sr-nHA coating on TC4 rods by plasma spraying, respectively.

TC4 rods coated with nHA or $10 \%$ Sr-nHA were immersed in the simulated body fluid (SBF, Qingdao Jie Shi Kang Biotechnology Co. Ltd., Qingdao, China) and the mineralization ability of coatings on TC4 rods was evaluated in vitro. SBF was changed every day. After 3 and 10 days, the rods immersed in SBF were subjected to SEM and XRD analyses.

\section{RESULTS AND DISCUSSION}

FTIR spectra showed that absorption bands of HA characteristic vibrations $\left(\mathrm{OH}^{-}\right.$and $\left.\mathrm{PO}_{4}{ }^{3-}\right)$ were observed in both nHA and Sr-nHA samples. The bands at 565 and $609 \mathrm{~cm}^{-1}$ were attributed to the bending mode of the O-P-O bonds. The bands associated to the stretching modes of $\mathrm{P}$ $\mathrm{O}$ bonds were observed at 962,1033 and $1081 \mathrm{~cm}^{-1}$. The bands at 631 and $3567 \mathrm{~cm}^{-1}$ were attributed to the bending (or vibration) and stretching modes of the hydroxyl groups, respectively [12]. Weak bands associated with carbonate $\left(\mathrm{CO}_{3}{ }^{2-}\right)$ were also detected (Fig. 1).

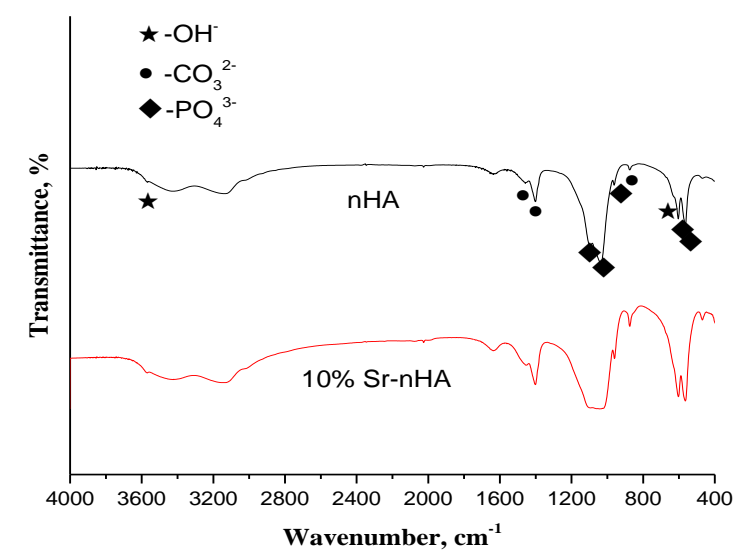

Fig. 1. FTIR Spectra of nHA and $10 \%$ Sr-nHA powders

As compared with the standard data, typical XRD diffraction peaks of HA were clearly identified in the prepared nHA and Sr-nHA samples (Fig. 2). The significant broadening of diffraction peaks indicated that the powders prepared in this study were nano-sized materials. Importantly, with the Sr substituting, special peak shifting was observed. The diffraction peaks move to small angles, which may be related to the larger radius of the strontium ions [23]. The lattice parameters of two powders were calculated with software and shown in Table 2. The Sr-nHA powder has lower crystallinity compared with the pure one.

Tiny nano-rods $(39.5 \pm 11.2 \mathrm{~nm}$ in length and $15.9 \pm 3.7 \mathrm{~nm}$ in width) are observed in the TEM micrographs of pure nHA sample. Compared with the pure nHA sample, the synthesized $10 \%$ Sr-nHA material has a smaller size with the length of $33.0 \pm 10.2 \mathrm{~nm}$ and the 
width of $13.2 \pm 3.2 \mathrm{~nm}$ (Fig. 3 and Table 3 ). The nano-size of both samples is similar to that of apatite crystallites in bone, which is generally $5-20 \mathrm{~nm}$ in width and $\sim 60 \mathrm{~nm}$ in length.

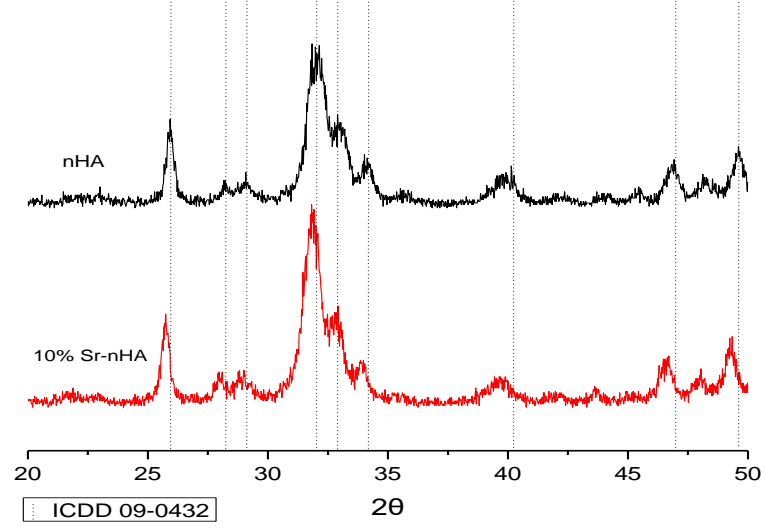

Fig. 2. XRD patterns of the synthesized powder samples

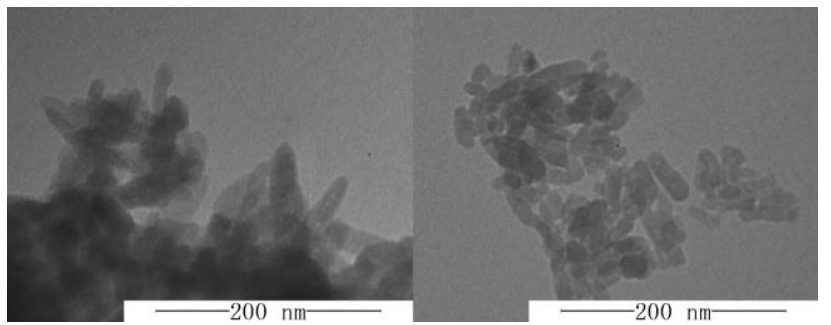

b

Fig. 3. TEM micrographs: $a-$ pure nHA; $b-10 \%$ Sr-nHA

In Fig. 4, some diffraction peaks of new products, which may be tricalcium phosphate $\left(\mathrm{Ca}_{3}\left(\mathrm{PO}_{4}\right)_{2}\right)$ and calcium monohydrogenphosphate $\left(\mathrm{CaHPO}_{4}\right)$, were observed in the XRD patterns except the typical peaks of HA (089-4405) and $10 \%$ Sr-HA (034-0484). All the peaks are weakened after spaying due to the instantaneous high temperature which may affect the crystallinity.

An undulating and potholed surface morphology of nHA and Sr-nHA coatings are shown in Fig. 5, which will facilitate the growth of cells in cytology experiments and good integration with surrounding bone tissues in vivo. The coatings consist mainly of cement-like hilly terrain as well as some globular particles in virtue of a higher degree of melting during spraying, which has been evidenced in XRD patterns after spraying.
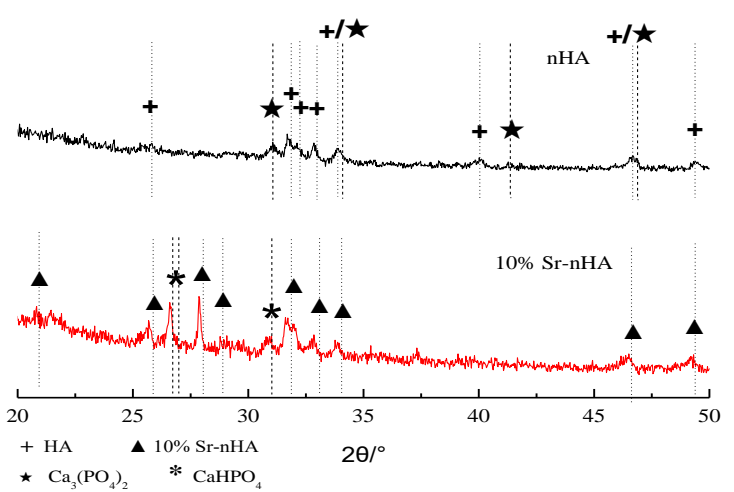

Fig. 4. XRD patterns of the nHA and the $10 \%$ Sr-nHA after spraying
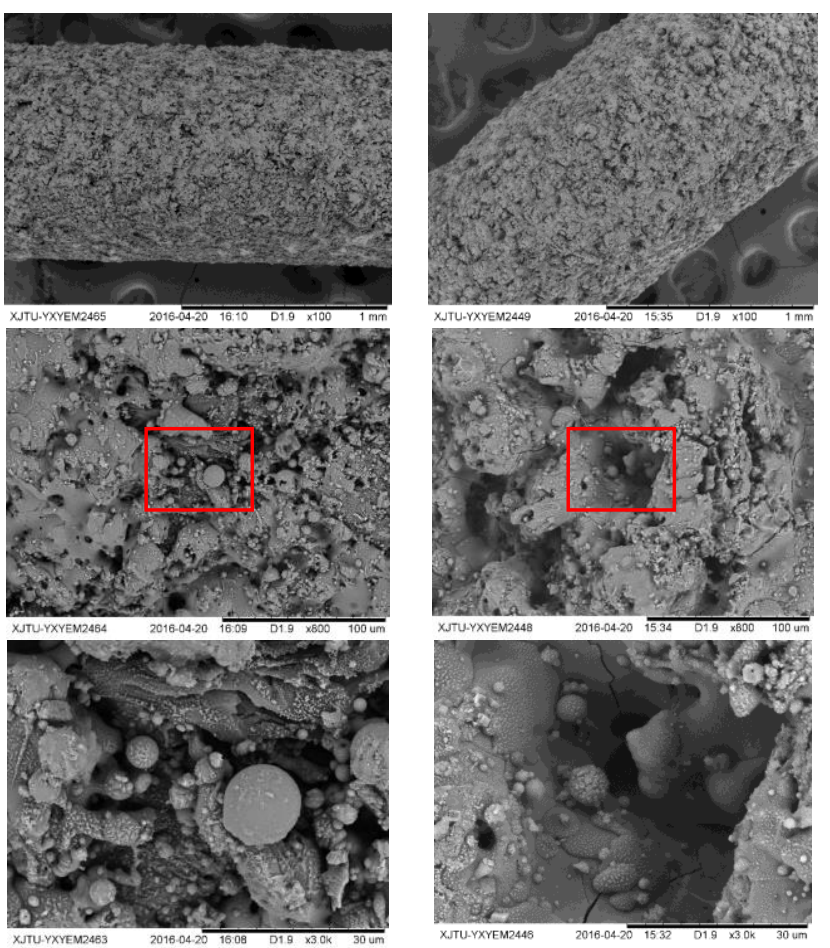

a

b

Fig. 5. SEM micrographs: a-nHA; b-10\% Sr-nHA after spraying

Some pores and micro-cracks without sandblasting layer were observed at the surface of the coating revealing the complete coverage and even thickness of the coatings.

Table 2. Lattice parameters of nHA and $10 \%$ Sr-nHA powders*

\begin{tabular}{|c|c|c|c|c|c|c|}
\hline sample & $2 \mathrm{~T} /{ }^{\circ}$ & $d(211)$ in $\AA$ & $a(211)$ in $\AA$ & $c(211)$ in $\AA$ & grain size & crystallinity \\
\hline Pure nHA & 31.962 & 2.7978 & 9.3576 & 6.8738 & $20.0 \mathrm{~nm}$ & $84.95 \%$ \\
\hline 10\% Sr-nHA & 31.844 & 2.8079 & 9.3859 & 6.9189 & $14.2 \mathrm{~nm}$ & $82.51 \%$ \\
\hline * software MDI Jade 6.5
\end{tabular}

Table 3. The length and width of synthesized nano-grains*

\begin{tabular}{|c|c|c|c|c|c|c|}
\hline sample & $\mathrm{N}$ & Mean, $\mathrm{nm}$ & SD & Max & Min & \multirow{3}{*}{$\mathrm{P}<0.05$} \\
\hline Length & 122 & 39.5 & 11.2 & 77.8 & 20.6 & \\
\hline $10 \%$ Sr-nHA & 155 & 33.0 & 10.2 & 24.0 & 7.7 & \\
\hline nHA & 122 & 15.9 & 3.7 & 72.1 & 13.0 & \multirow[t]{2}{*}{$\mathrm{P}<0.05$} \\
\hline $10 \%$ Sr-nHA & 155 & 13.2 & 3.2 & 22.7 & 7.3 & \\
\hline
\end{tabular}


Finally, EDS spectra (Fig. 6) clearly showed the presence of not only $\mathrm{Ca}, \mathrm{O}, \mathrm{P}$ but also $\mathrm{Sr}$ in the $10 \% \mathrm{Sr}-$ nHA coating sample. The weight ratio and atom ratio of all the elements were listed in Table 4 and Table 5. The atomic ratio of $\mathrm{Sr} /(\mathrm{Ca}+\mathrm{Sr})$ in Table 5 is approximately $10 \%$. The atomic ratios of $\mathrm{Ca} / \mathrm{P}$ in Table 4 and $(\mathrm{Ca}+\mathrm{Sr}) / \mathrm{P}$ in Table 5 are approximately 10/6, which is the atomic ratio of $\mathrm{Ca} / \mathrm{P}$ in $\mathrm{HA}$. It is in agreement with the XRD results that there is nearly unchanged phase composition after spraying, although $\mathrm{Ca}_{3}\left(\mathrm{PO}_{4}\right)_{2}$ and $\mathrm{CaHPO}_{4}$ appeared after spraying, which have low atomic ratio of $\mathrm{Ca} / \mathrm{P}$.

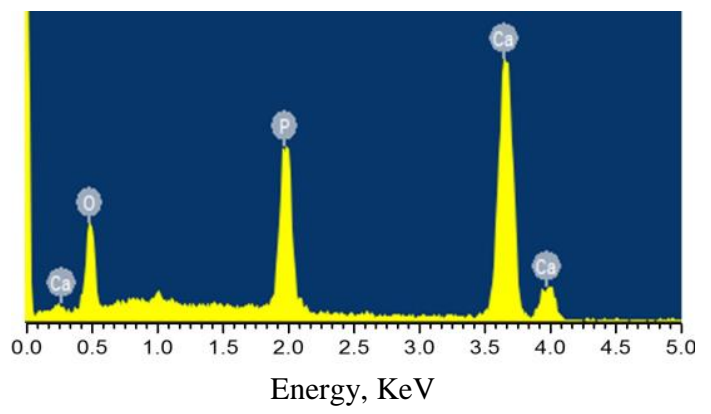

a

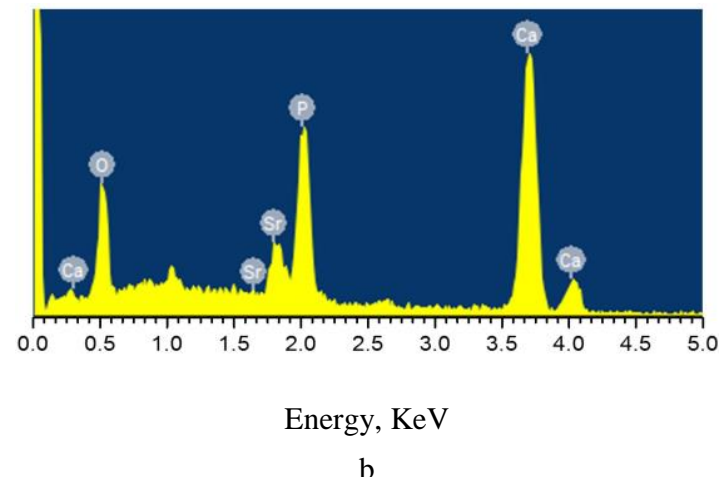

Fig. 6. EDS results: $a-$ synthesized pure nHA; $b-10 \%$ Sr-nHA coating samples

Table 4. EDS result of nHA

\begin{tabular}{|c|c|c|}
\hline Elements & Weight, $\%$ & Atom, $\%$ \\
\hline O K & 50.5 & 70.1 \\
\hline P K & 15.3 & 11.0 \\
\hline Ca K & 34.2 & 19.0 \\
\hline Total & 100.0 & 100 \\
\hline
\end{tabular}

Immersion in SBF was carried out to detect in vitro mineralization behaviour of $\mathrm{nHA}$ and $10 \% \quad \mathrm{Sr}-\mathrm{HA}$ coatings. After 3 day of immersion in SBF, some white needle crystal or crystalline powder apatite were observed on the coatings (Fig. $7 \mathrm{a}$ and b). After one more week, the coating surface was completely covered with apatite deposit (Fig. $7 \mathrm{c}$ and d).

Compared to the Fig. 4, some diffraction peaks of HA appeared in the region of small angles and other peaks become obvious. Compared with the pure nHA coating, $10 \%$ Sr-HA coating showed the stronger ability to induce Ca-P deposition (Fig. 8). The deposition of Ca-P on Sr-HA coating consists of a dissolution and precipitation process. It has been demonstrated that the doping of $\mathrm{Sr}$ can increase HA solubility [27, 28]. The dissolution of the Sr-HA coating could be the first step and is also required for the formation of apatite deposit in SBF.
Table 5. EDS result of 10\% Sr-nHA

\begin{tabular}{|c|c|c|}
\hline Elements & Weight, $\%$ & Atom, $\%$ \\
\hline O K & 50.3 & 71.7 \\
\hline P K & 14.2 & 10.4 \\
\hline Ca K & 27.7 & 15.8 \\
\hline Sr L & 7.9 & 2.1 \\
\hline Total & 100.0 & 100 \\
\hline
\end{tabular}

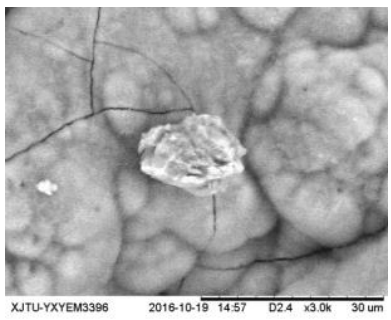

a

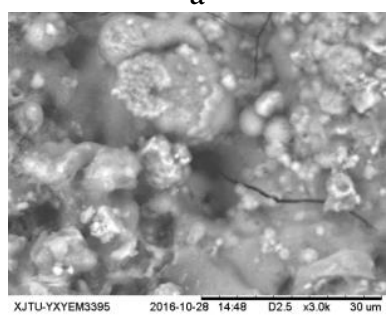

c

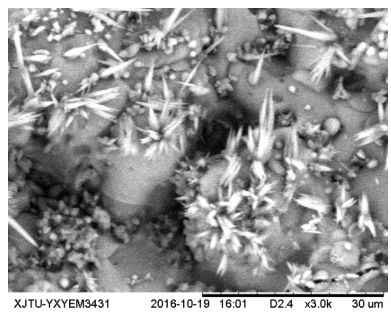

b

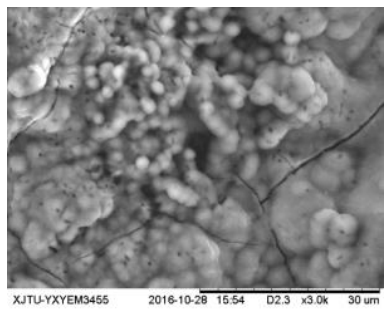

d
Fig. 7. SEM micrographs of nHA and $10 \%$ Sr-nHA coatings after SBF test. a-nHA, 3d, b-Sr-nHA, 3d, c-nHA, 10 d, d-Sr-nHA, $10 \mathrm{~d}$

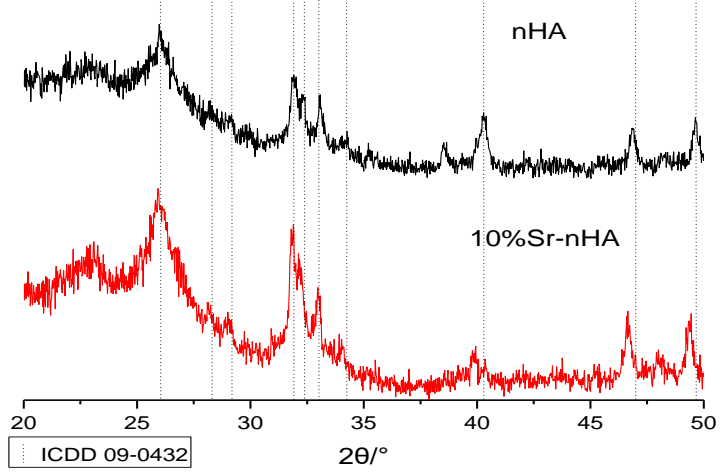

Fig. 8. XRD patterns of the pure nHA and the $10 \% \mathrm{Sr}$-nHA coating samples after immersion in SBF for 3 days.

This study involves the powder synthesis, plasma spraying and in vitro mineralization assessment. Compared with related investigations, our powder samples have smaller crystallite sizes $[12,23]$. For clinical application, cytological and in vivo tests will be carried out later based on the above results. By culturing osteoblasts on the different coated rods, the compatibility, proliferation and genes protein expression of osteoblasts would be evaluated from the cellular level. Total protein content, intracellular calcium content and alkaline phosphatase activity will be tested and the expression of OPG, Osterix, Runx2, and BMP will be observed. Afterwards, in vivo animal experiments would be carried out to checkout coatings in vivo. Histochemical staining and micro-CT will be used to observe new bone formation and the connection between coating and tissue. 


\section{CONCLUSIONS}

In this study, the pure nHA and $10 \% \mathrm{Sr}$-nHA powders were synthesized and plasma sprayed on $\varnothing 1 \mathrm{~mm}$ TC4 rods. Moreover, the rods coated with $10 \%$ Sr-nHA showed higher mineralization ability than those coated with pure nHA. Therefore, the Sr-nHA powder and coating prepared in this study are expected to be further explored for biomedical applications in orthopaedics.

\section{Acknowledgments}

This work was financially supported by the Science and Technology Programs of Shaanxi Province (2012KW08, 2015JM5152) and partially supported by the National Natural Science Foundation of China (81672187).

\section{REFERENCES}

1. Laires, P.A., Perelman, J., Consciencia, J.G., Monteiro, J., Branco, J.C. Epidemiology of Hip Fractures and Its Social and Economic Impact. An Update for 2014 Acta Reumatol Port 40 (3) 2015: pp. 223 -230.

2. Lange, A., Zeidler, J., Braun, S. One-Year Disease-Related Health Care Costs of Incident Vertebral Fractures in Osteoporotic Patients Osteoporosis International 25 (10) 2014: pp. 2435 - 2443.

3. Svedbom, A., Hernlund, E., Ivergard, M., Compston, J., Cooper, C., Stenmark, J., McCloskey, E.V., Jonsson, B., Kanis, J.A. Osteoporosis in the European Union: A Compendium of Country-Specific Reports Archives of Osteoporosis $8(1-2)$ 2013: pp. 1-218.

4. Mithal, A., Kaur, P. Osteoporosis in Asia: A Call to Action Current Osteoporosis Reports 10 (4) 2012: pp. 245-247.

5. Bellucci, D., Sola, A., Cannillo, V. Hydroxyapatite and Tricalcium Phosphate Composites with Bioactive Glass as Second Phase: State of the Art and Current Applications Journal of Biomedical Materials Research. Part A 104 (4) 2016: pp. $1030-1056$.

6. Li, Z., Khun, N.W., Tang, X.Z., Liu, E., Khor, K.A. Mechanical, Tribological and Biological Properties of Novel 45s5 Bioglass(R) Composites Reinforced with in Situ Reduced Graphene Oxide Journal of the Mechanical Behavior of Biomedical Materials 65 2016: pp. 77-89. https://doi.org/10.1016/j.jmbbm.2016.08.007

7. Yang, J., Zhang, K., Zhang, S., Fan, J., Guo, X., Dong, W., Wang, S., Chen, Y., Yu, B. Preparation of Calcium Phosphate Cement and Polymethyl Methacrylate for Biological Composite Bone Cements Medical Science Monitor 21 2015: pp. 1162-1172.

8. Qiao, Y., Zhai, Z., Chen, L., Liu, H. Cytocompatible 3d Chitosan/Hydroxyapatite Composites Endowed with Antibacterial Properties: Toward a Self-Sterilized Bone Tissue Engineering Scaffold Science Bulletin $60(13)$ 2015: pp. 1193 - 1202 .

9. Hasan, M.S., Carpenter, N., Wei, T.L., McNally, D., Ahmed, I., Boszczyk, B.M. Effects of Adding Resorbable Phosphate Glass Fibres and Pla to Calcium Phosphate Bone Cements Journal of Applied Biomaterials \& Functional Materials 12 (3) 2014: pp. 203-209.

10. Mehrali, M., Baradaran, S., Moghaddam, E., Mehrali, M.,

Shirazi, S.F., Metselaar, H.S Kadri, N. Latibari, S.T. Synthesis, Mechanical Properties, and in Vitro
Biocompatibility with Osteoblasts of Calcium SilicateReduced Graphene Oxide Composites ACS Applied Materials \& Interfaces 6 (6) 2014: pp. 3947-3962. https://doi.org/10.1021/am500845x

11. Tao, Z.S., Bai, B.L., He, X.W., Liu, W., Li, H., Zhou, Q., Sun, T., Huang, Z.L., Tu, K.K., Lv, Y.X., Cui, W., Yang, L. A Comparative Study of Strontium-Substituted Hydroxyapatite Coating on Implant's Osseointegration for Osteopenic Rats Medical \& Biological Engineering \& Computing 54 (12) 2016: pp. 1959-1968.

12. Kaygili, O., Keser, S., Kom, M., $\quad$ Eroksuz, Y., Dorozhkin, S.V., Ates, T., Ozercan, I.H., Tatar, C., Yakuphanoglu, F. Strontium Substituted Hydroxyapatites: Synthesis and Determination of Their Structural Properties, in Vitro and in Vivo Performance Materials Science \& Engineering C, Materials for Biological Applications 55 2015: pp. $538-546$. https://doi.org/10.1016/j.msec.2015.05.081

13. Li, Y., Luo, E., Zhu, S., Li, J., Zhang, L., Hu, J. Cancellous Bone Response to Strontium-Doped Hydroxyapatite in Osteoporotic Rats Journal of Applied Biomaterials \& Functional Materials $13(1)$ 2015: pp. 28-34.

14. Ma, X., Wang, Y., Guo, H., Wang, J. NanoHydroxyapatite/Chitosan Sponge-Like Biocomposite for Repairing of Rat Calvarial Critical-Sized Bone Defect Journal of Bioactive \& Compatible Polymers 26 (4) 2011: pp. 335-346. https://doi.org/10.1177/0883911511407402

15. Ma, X., Liu, Y., Wu, X.M., Wang, C., Li, Q., Fu, T. Synthesis of Europium-Doped Nanohydroxyapatite and Its Cytocompatibility with Endothelial Cells in Vitro Materials Technology 31 (S1) 2016: pp. 23-27.

16. Cox, S.C., Jamshidi, P., Grover, L.M., Mallick, K.K. Preparation and Characterisation of Nanophase Sr, Mg, and Zn Substituted Hydroxyapatite by Aqueous Precipitation Materials Science \& Engineering. C, Materials for Biological Applications 35 2014: pp. 106-114. https://doi.org/10.1016/j.msec.2013.10.015

17. Boanini, E., Torricelli, P., Sima, F., Axente, E., Fini, M., Mihailescu, I.N., Bigi, A. Strontium and Zoledronate Hydroxyapatites Graded Composite Coatings for Bone Prostheses Journal of Colloid and Interface Science 448 2015: pp. 1-7.

18. Zhang, N., Zhai, D., Chen, L., Zou, Z., Lin, K., Chang, J. Hydrothermal Synthesis and Characterization of $\mathrm{Si}$ and $\mathrm{Sr}$ Co-Substituted Hydroxyapatite Nanowires Using Strontium Containing Calcium Silicate as Precursors Materials Science \& Engineering. C, Materials for Biological Applications 37 2014: pp. 286-291. https://doi.org/10.1016/j.msec.2014.01.011

19. Querido, W., Rossi, A.L., Farina, M. The Effects of Strontium on Bone Mineral: A Review on Current Knowledge and Microanalytical Approaches Micron 80 2016: pp. $122-134$.

20. Masala, S., Taglieri, A., Chiaravalloti, A., Calabria, E., Morini, M., Iundusi, R., Tarantino, U., Simonetti, G. Thoraco-Lumbar Traumatic Vertebral Fractures Augmentation by Osteo-Conductive and Osteo-Inductive Bone Substitute Containing Strontium-Hydroxyapatite: Our Experience Neuroradiology 56 (6) 2014: pp. 459-466. https://doi.org/10.1007/s00234-014-1351-1

21. Cardemil, C., Elgali, I., Xia, W., Emanuelsson, L., Norlindh, B., Omar, O., Thomsen, P. Strontium-Doped Calcium Phosphate and Hydroxyapatite Granules Promote 
Different Inflammatory and Bone Remodelling Responses in Normal and Ovariectomised Rats PloS One 8 (12) 2013: pp. e84932.

22. Yatongchai, C., Wren, A.W., Curran, D.J., Hornez, J.C., Mark, R.T. Comparison of the Weibull Characteristics of Hydroxyapatite and Strontium Doped Hydroxyapatite Journal of the Mechanical Behavior of Biomedical Materials 21 2013: pp. 95-108. https://doi.org/10.1016/j.jmbbm.2013.02.004

23. Kavitha, M., $\quad$ Subramanian, R., Narayanan, R., Udhayabanu, V. Solution Combustion Synthesis and Characterization of Strontium Substituted Hydroxyapatite Nanocrystals Powder Technology 253 2014: pp. 129-137.

24. Boyd, A.R., Rutledge, L., Randolph, L.D., Meenan, B.J. Strontium-Substituted Hydroxyapatite Coatings Deposited Via a Co-Deposition Sputter Technique Materials Science \& Engineering. C, Materials for Biological Applications 46 2015: pp. $290-300$.

https://doi.org/10.1016/j.msec.2014.10.046
25. Ozeki, K., Goto, T., Aoki, H., Masuzawa, T. Characterization of Sr-Substituted Hydroxyapatite Thin Film by Sputtering Technique from Mixture Targets of Hydroxyapatite and Strontium Apatite Bio-medical Materials and Engineering 24 (2) 2014: pp. 1447-1456.

26. Curran, D.J., Fleming, T.J., Towler, M.R., Hampshire, S. Mechanical Parameters of Strontium Doped Hydroxyapatite Sintered Using Microwave and Conventional Methods Journal of the Mechanical Behavior of Biomedical Materials 4 (8) 2011: pp. 2063-2073.

27. Xue, W., Hosick, H.L., Bandyopadhyay, A., Bose, S., Ding, C., Luk, K.D.K., Cheung, K.M.C., Lu, W.W. Preparation and Cell-Materials Interactions of Plasma Sprayed Strontium-Containing Hydroxyapatite Coating Surface \& Coatings Technology $201(8)$ 2007: pp. $4685-4693$.

28. Christoffersen, J., Christoffersen, M.R., Kolthoff, N., Barenholdt, O. Effects of Strontium Ions on Growth and Dissolution of Hydroxyapatite and on Bone Mineral Detection Bone 20 (1) 1997: pp. 47-54. 